\title{
Phonology and orthography in reading aloud
}

\author{
NiELS O. SCHILleR \\ Maastricht University, Maastricht, The Netherlands \\ Max Planck Institute for Psycholinguistics, Nijmegen, The Netherlands \\ and Leiden Institute for Brain and Cognition, Leiden, The Netherlands
}

\begin{abstract}
This study investigated the orthographic and phonological contribution of visually masked primes to reading aloud in Dutch. Although there is a relatively clear mapping between the spelling and sound of words in Dutch, words starting with the letter $c$ are ambiguous as to whether they begin with the phoneme /s/ (e.g., citroen, "lemon") or with the phoneme /k/ (e.g., complot, "conspiracy"). Therefore, using words of this type, one can tease apart the contributions of orthographic and phonological activation in reading aloud. Dutch participants read aloud bisyllabic $c$-initial target words, which were preceded by visually masked, bisyllabic prime words that either shared the initial phoneme with the target (phonologically related) or the first grapheme (orthographically related) or both (phonologically and orthographically related). Unrelated primes did not share the first segment with the target. Response latencies in the phonologically related conditions were shorter than those in the unrelated condition. However, primes that were orthographically related did not speed up responses. One may conclude that the nature of the onset effect in reading aloud is phonological and not orthographic.
\end{abstract}

Visual word recognition comprises the processes involved in identifying a word-for instance, during reading (see, e.g., Coltheart, Rastle, Perry, Langdon, \& Ziegler, 2001). One important theoretical issue in visual word recognition concerns the role of phonology (see Frost, 1998, for a review). In principle, the orthographic representation could be enough to recognize visually presented words. However, it has been shown that the phonology of words also has a considerable impact on visual word recognition. For instance, Yates, Locker, and Simpson (2004) showed that phonological neighborhood influenced visual word perception (see also Mulatti, Reynolds, \& Besner, 2006). In a visual lexical decision task, participants responded more rapidly and accurately to words with larger phonological neighborhoods than to those with smaller neighborhoods. Presumably, words with many phonological neighbors lead to a stronger pattern of activation at the phonological level than words with fewer neighbors. This activation pattern is an indication for the word recognition system that a letter string is a word, thus allowing faster responses. Yates et al. (2004) concluded that their results demonstrate the importance of phonological codes when processing letter strings. Yates (2005) replicated these findings using the naming and semantic categorization tasks.

Similarly, Perfetti, Bell, and Delaney (1988)—using a backward visual masking procedure- demonstrated a higher target word (e.g., phase) identification accuracy when the backward mask was homophonic with the target (e.g., FAYZE) than when it was a graphemic mask (e.g., FARNE) or a control mask (e.g., COMPT). Perfetti et al. (1988) suggested that phonological information of words is quickly activated during reading and assists visual word identification in an early stage. This early role of phonology in visual word recognition was supported by another study of Perfetti and Bell (1991) showing that phonological priming effects reflect phonemic activation of the target words within $45 \mathrm{msec}$ of prime exposure duration.

Ferrand and Grainger $(1992,1993,1994)$ extended these results in a systematic time course study of visual word recognition using masked priming. They demonstrated orthographic priming effects with prime exposure durations as short as $17 \mathrm{msec}$ in lexical decision. Phonological priming started to emerge around $50 \mathrm{msec}$, which corresponds to the results reported by Perfetti and colleagues that were mentioned previously. Ferrand and Grainger $(1992,1993)$ developed an interactive activation model of word recognition in which orthographic information is fed directly into the lexicon and into phonological representations. These phonological representations can also feed into the lexicon (word level). However, phonological priming effects are mediated by orthographic representations. Therefore, this model predicts that effects of pseudohomophone primes (e.g., mert) that have orthographic overlap with a target (e.g., MERE) should appear earlier than the effects of pseudohomophones with less orthographic overlap (e.g., mair). In a lexical decision experiment reported in Ferrand and Grainger (1994, Experiment 1), orthographic priming (e.g., mert-MERE) yielded a significant facilitation effect (compared with an unrelated control condition) at 29-msec prime exposure duration, whereas phonological priming (e.g., mair-MERE) became significant slightly later-that is, between 29 and $57 \mathrm{msec}$, supporting their model.

N. O. Schiller, n.o.schiller@let.leidenuniv.nl 
However, in the latter experiment, there was still the problem of shared onsets - that is, a rest-of-orthographic similarity in the latter condition (mair-MERE vs. mert-MERE). Previous work has shown that the onset plays an important role in word processing, especially in reading aloud (see, e.g., Forster \& Davis, 1991; Kinoshita, 2000, 2003; Schiller, 2004, in press). When Ferrand and Grainger (1994) included a nonhomophonic, orthographically related prime (e.g., merq-MERE) in their second lexical decision experiment as an appropriate control condition (instead of an all-letter-different control prime), any phonological priming effect (e.g., mair-MERE) disappeared at 29-msec prime exposure duration, whereas the orthographic priming effect (e.g., mert-MERE) remained clearly significant. These data are taken as strong support for the hypothesis that orthographic information plays an early role in visual word recognition, earlier than phonological information.

Interestingly, when the onset was replaced by a percent sign in a French word naming experiment, Grainger and Ferrand (1996) found that rhyming primes (e.g., \%ert) yielded shorter naming latencies for target words (e.g., NERF) than nonrhyming primes (e.g., \%erc) at $43 \mathrm{msec}$ prime exposure duration. Grainger and Ferrand concluded that these results add further support to the hypothesis that masked phonological priming effects reflect the automatic generation of (prelexical) phonology from printed words, as was suggested by Perfetti et al. (1988). In summary, Ferrand and Grainger's (1992) model seems to capture the time lag between the activation of orthographic and phonological information in visual word recognition. This time lag is estimated to be approximately $30 \mathrm{msec}$.

In sum, the time course of orthographic and phonological contributions seems to indicate that orthographic information plays an earlier role than phonological information. However, the Ferrand and Grainger (1993) data suggest that orthography and phonology can be activated at the same time in word identification-for instance, when the prime exposure duration is about $50 \mathrm{msec}$. The present study tried to disentangle the contributions of orthography and phonology to visual word recognition by using the masked priming paradigm with this prime exposure duration (i.e., $50 \mathrm{msec}$ ) in a language with a shallow orthography - that is, Dutch.

\section{Reading Aloud With Onset-Related Masked Primes}

Dutch has a shallow orthography: Letters are usually pronounced in only one possible way. Therefore, in word processing tasks, orthographic and phonological factors are most often confounded in Dutch as well as in many other languages (e.g., Spanish, Italian, German, etc.). However, there are some Dutch words that systematically vary in pronunciation, although they start with the same letter. The pronunciation of words starting with the letter $c$ ( $c$-words hereafter) depends on the following segment. If the following segment is a so-called front vowel (e.g., /i/, /e/, etc.) or a diphthong ending in a front vowel (e.g., /عI/, etc.), then the onset of a $c$-word is pronounced like the phoneme /s/ -for example, cement (/sement/, "concrete"). In contrast, the onset of a $c$-word is pronounced like the phoneme $/ \mathrm{k} /$ if the second segment is either a so-called back vowel, such as /o/ or /a/ (e.g., congres, /kon $\chi \mathrm{res} /$, "congress") or another consonant (e.g., creatie, /kreatsi/, "creation"). That is, $c$-words in Dutch are not irregular, since their pronunciation is rule governed. Therefore, $c$-words form a test case for the question of whether the onset priming effect is orthographic or phonological in nature, because the two effects can be disentangled for this class of words.

\section{METHOD}

\section{Participants}

Twenty-eight participants from Radboud University Nijmegen took part in the experiment. All participants were native speakers of Dutch and had normal or corrected-to-normal vision. They were paid for their participation in the experiment.

\section{Procedure}

The specific masked priming procedure used in this study was the so-called four-field masked priming procedure (described in Ferrand, Grainger, \& Segui, 1994) and was very similar to the one used in Schiller $(1998,2000)$. Participants were tested individually in a dimly lit, soundproof room. Participants were seated about $60 \mathrm{~cm}$ from a computer screen. Target words appeared in white capital letters on a black screen and remained in view until a response was given, or maximally $2,000 \mathrm{msec}$. Before the presentation of a target, a fixation point appeared for $500 \mathrm{msec}$ in the middle of the screen at which participants were asked to look. Then a row of ten hash marks (\#s) appeared for $500 \mathrm{msec}$ as a forward mask and replaced the fixation point. Immediately afterwards, the prime was presented in lower case for $50 \mathrm{msec}$, followed by a backward mask for $17 \mathrm{msec}$, which was identical to the forward mask. The target immediately replaced the backward mask. Participants were requested to read aloud the target words as fast and as accurately as possible. ${ }^{1}$

All stimuli were centered on the screen. Preceding and following the prime word, percent signs ("\%") were added until the prime matched the number of characters of the masks. This procedure was used to avoid additional flickering on the screen that was due to the presentation of stimuli differing in length. Response latencies (reaction times, RTs hereafter) were measured from the target onset with a microphone connected to a voice key. Trial sequencing was controlled by Nijmegen experimental set-up (NESU). The presence of a prime was not mentioned to the participants. Participants were instructed to read the target word aloud as fast as possible while avoiding errors. When a response was given, the next trial started after 1,000 msec.

\section{Design}

Across the experiment, each critical target was preceded by five primes: a phonologically and orthographically congruent $(\mathrm{P}+\mathrm{O}+)$ word (e.g., canvas-CONGRES), a phonologically congruent but orthographically incongruent ( $\mathrm{P}+\mathrm{O}-$ ) word (e.g., kachel-CONGRES), a phonologically incongruent but orthographically congruent $(\mathrm{P}-\mathrm{O}+)$ word (e.g., cement-CONGRES), an unrelated $(\mathrm{P}-\mathrm{O}-$ ) word (e.g., grendel-CONGRES), or a control prime (e.g., $\% \% \% \% \% \% \% \% \% \%-$ CONGRES). Half of the critical targets started with an $/ \mathrm{s} /$, and the other half started with a $/ \mathrm{k} /$. Half of the targets served as $\mathrm{P}-\mathrm{O}+$ primes for the other half of the targets, and vice versa. $\mathrm{P}+\mathrm{O}-$ primes started either with the letter $s$ or $k$. Each participant received the total of 120 randomized test trials ( 24 words $\times 5$ priming conditions) that were split into two blocks with a short break in between. The order of blocks was counterbalanced for each participant. At the beginning of each block, there were five warm-up trials not starting with a $c$ and paired with control primes ( $\%$ signs).

\section{Materials}

The materials consisted of 24 words starting with the letter $c$. Half of the words started with the phoneme /s/ (e.g., cement), and the other half had $/ \mathrm{k} /$ as the onset phoneme (e.g., congres). Target 
words had a mean frequency of occurrence of 11.1 per one million word forms (according to CELEX; Baayen, Piepenbrock, \& Gulikers, 1995) and a mean neighborhood density of 6.69. All target and prime words can be found in the Appendix.

\section{RESULTS}

Response latencies that were shorter than $300 \mathrm{msec}$ and longer than $1,000 \mathrm{msec}$ were counted as outliers $(0.6 \%$ of the data) and discarded from the analyses. The mean response latencies and percentage errors are summarized in Table 1. Separate analyses were carried out with participants $\left(F_{1}\right)$ and items $\left(F_{2}\right)$ as random variables. ANOVAs were run with phonological congruency and orthographic congruency as the independent variables.

\section{Response Latencies}

The main effect of phonological congruency was significant $\left[F_{1}(1,27)=31.76, M S_{\mathrm{e}}=165.22, p<.001\right.$; $\left.F_{2}(1,23)=16.84, M S_{\mathrm{e}}=101.23, p<.001\right]$. Primes that were phonologically congruent with the target yielded RTs that were on average $14 \mathrm{msec}$ faster than primes that were phonologically incongruent with the target. The main effect of orthographic congruency was not significant $\left[F_{1}(1,27)=\right.$ 4.98, $\left.M S_{\mathrm{e}}=490.68, p<.05 ; F_{2}(1,23)<1\right]$. Primes that were orthographically congruent with the target yielded RTs that were on average $4 \mathrm{msec}$ slower than primes that were orthographically incongruent with the target. Phonological and orthographic congruency did not interact $\left[F_{1}(1,27)<1 ; F_{2}(1,23)=2.44, M S_{\mathrm{e}}=93.89\right.$, n.s. $]$.

Paired-sample $t$ tests were carried out to compare the effects of the individual conditions with each other and with the control condition. When the primes were phonologically congruent with the target $(\mathrm{P}+\mathrm{O}-$ or $\mathrm{P}+\mathrm{O}+)$, there was a priming effect, in comparison with the unrelated condition. Pair-wise comparisons (Bonferroni adjusted $\alpha=.005)$ showed that $\mathrm{P}+\mathrm{O}-$ primes $(514 \mathrm{msec})$ yielded a significant facilitation effect when compared with the $\mathrm{P}-\mathrm{O}-\left[529 \mathrm{msec}, t_{1}(27)=3.34, S D=24.53\right.$, $\left.p<.005 ; t_{2}(23)=4.53, S D=12.46, p<.005\right]$ and the $\mathrm{P}-\mathrm{O}+\left[532 \mathrm{msec}, t_{1}(27)=5.32, S D=17.79, p<.005\right.$; $\left.t_{2}(23)=4.09, S D=11.28, p<.005\right]$ condition, but missed significance in the item analysis in comparison with the control condition [ $528 \mathrm{msec}, t_{1}(27)=3.95, S D=$ $18.81, p<.005 ; t_{2}(23)=1.39, S D=16.60$, n.s. $] . \mathrm{P}+\mathrm{O}+$ primes $(519 \mathrm{msec})$ yielded a significant facilitation effect in comparison with the unrelated $\mathrm{P}-\mathrm{O}-$ [only significant by participants, $t_{1}(27)=3.46, S D=14.53, p<.005$; $\left.t_{2}(23)=2.00, S D=18.21, p=.057\right]$ and the $\mathrm{P}-\mathrm{O}+$ condition [also only significant by participants, $t_{1}(27)=2.99$, $S D=21.06, p<.005 ; t_{2}(23)=1.71, S D=15.33$, n.s. $]$ but not with the control condition, despite a 9-msec difference $\left[t_{1}(27)=2.27, S D=18.84, p=.032 ; t_{2}(23)<1\right]$. Interestingly, the $\mathrm{P}+\mathrm{O}+$ and the $\mathrm{P}+\mathrm{O}-$ condition were not different from each other $\left[t_{1}(27)=1.68, S D=18.74\right.$, n.s.; $t_{2}(23)=1.24, S D=16.06$, n.s.]. This result demonstrates that there was no facilitation from a matching orthographic onset for $c$-words, indicating the lack of an orthographic contribution when phonology is controlled for. Furthermore, $\mathrm{P}-\mathrm{O}+, \mathrm{P}-\mathrm{O}-$, and the control condi- tion were no different from each other (all $p \mathrm{~s}>.10$ ), emphasizing once again the importance of the phonological onset match and indicating that orthography seems to play a limited role in reading aloud in Dutch.

\section{Percentage Errors}

The overall percentage error was $1.9 \%$. The main effect of phonological congruency was not significant $\left[F_{1}(1,27)<1\right.$; $\left.F_{2}(1,23)<1\right]$. The main effect of orthographic congruency was significant only by items $\left[F_{1}(1,27)=2.96, M S_{\mathrm{e}}=\right.$ 0.43 , n.s.; $\left.F_{2}(1,23)=6.93, M S_{\mathrm{e}}=0.60, p<.05\right]$, and the interaction between phonological and orthographic congruency was not significant $\left[F_{1}(1,27)=1.13, M S_{\mathrm{e}}=0.28\right.$, n.s.; $F_{2}(1,23)=1.64, M S_{\mathrm{e}}=0.41$, n.s.].

\section{DISCUSSION}

The experiment clearly supports the view that the onset priming effect has a strong phonological component in Dutch. When the prime was phonologically but not orthographically congruent with the target, participants were significantly faster in reading the target aloud than they were in the control condition. However, when the situation was reversed-that is, when primes were orthographically but not phonologically congruent with the targetsreading aloud was just as slow as it was in the unrelated condition, indicating a limited role for orthography in Dutch; that is, a language with a relatively clear relationship between spelling and sound. This inhibition effect is presumably due to mismatching phonological information at the word onset. Furthermore, the $\mathrm{P}+\mathrm{O}+$ condition was not different from the $\mathrm{P}+\mathrm{O}-$ condition. That is, orthographic congruency between prime and target does not facilitate reading aloud over and above phonological congruency. On the contrary, orthographic congruency did not facilitate responses in this study at all. ${ }^{2}$

Damian (2001) — using visually masked prime wordsshowed that congruency effects in a semantic decision task were due to quickly acquired stimulus-response mappings rather than unconscious prime categorization. Due to material selection constraints, it was necessary to use targets also as primes in the present study. Therefore, one may argue that the current results are due to a similar stimulus-response mapping $(c \rightarrow / \mathrm{k} /$ and $c \rightarrow / \mathrm{s} /)$ rather than a phonological onset effect. However, this is unlikely for the following reason: In the $\mathrm{P}-\mathrm{O}+$ condition (e.g., cement-CONGRES and congres-CEMENT) and in the $\mathrm{P}+\mathrm{O}+$ condition (e.g., canvas-CONGRES and cycloon-CEMENT), the same set of primes was used in the present experiment. Moreover, both of these primes - that is, $\mathrm{P}-\mathrm{O}+$ and $\mathrm{P}+\mathrm{O}+$ - occurred as targets. Critically, however, the $\mathrm{P}+\mathrm{O}+$ condition but not the $\mathrm{P}-\mathrm{O}+$ condition produced priming. Therefore, the difference in priming between these two conditions cannot be explained in terms of stimulus-response mapping alone.

There is another area of language processing in which form priming effects are likely to be phonological in nature - that is, picture naming. To name a picture, participants do not necessarily have to activate the orthographic representation of the target (but see Damian \& Bowers, 
2003, and Lupker, 1982). For instance, Ferrand, Grainger, and Segui (1994) carried out picture naming experiments in French in which visually masked nonword primes were either homophonic and orthographically similar to the target picture name (e.g., piez-PIED), orthographically similar but not homophonic (e.g., pien-PIED), or shared the first segment with the target but were otherwise unrelated (e.g., peul-PIED). The orthographically similar but nonhomophonic primes did not differ from the unrelated primes, whereas the homophonic primes yielded between 51-msec (Experiment 2A) and 31-msec (Experiment 3) facilitation. These results suggest that the underlying representation that is activated by a masked prime in picture naming is phonological (Ferrand et al., 1994). Together with the priming effects for picture targets in Dutch (Schiller, 1998, Experiment 2) and English (Schiller, 2000, Experiment 2), the present results strongly suggest that the main component of form priming in Dutch naming tasks is phonological in nature.

Supporting this point of view, Kinoshita (2000) argued that the onset priming effect in reading aloud has its locus in speech production planning rather than in orthographyto-phonology conversion. In Experiment 1 of her study, she found that sharing the initial letter between prime and target (e.g., suf-SIB) but not the final letter (e.g., $m u b-\mathrm{SIB}$ ) facilitated reading aloud. Her second experiment revealed that this masked onset priming effect was due to sharing the onset (e.g., penny-PASTE) rather than the initial letter without the onset (e.g., bingo-BLIss; but see Schiller, 2004). Therefore, Kinoshita (2000) argued that the sequential nature of the masked onset priming effect may reflect a characteristic of the speech production system, which facilitates articulatory planning once the onset is selected, rather than the nonlexical computation of phonology from orthography (Coltheart et al., 2001; Forster \& Davis, 1991). The present results are consistent with Kinoshita's view.

Interestingly, Damian and Bowers (2003) also conducted a study testing words starting with $c$ (e.g., coffee) and with $k$ (e.g., kennel) in English. Using the implicit priming or preparation paradigm (see Levelt, Roelofs, \& Meyer, 1999, for an overview), they showed that words that share the initial sound but differ in spelling do not yield a preparation effect. This result is not in line with our previously presented results. However, in another experiment, Damian and Bowers (2003) showed that words matching in the initial letter but not in sound (e.g., cycle and cobra) did not yield a preparation effect either. This latter result is important because it provides evidence from a nonshallow language (i.e., English) that fits the data that are presented in the present study. Damian and Bowers (2003) raised the possibility that both phonological and orthographic codes are activated automatically during language production.

However, Roelofs (2006) carried out a study in Dutch that was inspired by the results of Damian and Bowers (2003). Roelofs demonstrated that in tasks in which spelling is irrelevant (e.g., picture naming or word generation), the response preparation effect was not disrupted when targets had the same initial phoneme but differed in spelling (e.g., citroen, "lemon," sigaar, "cigar," soldaat, "soldier"; or kompas, "compass," colbert, "jacket," ca- deau, "present"). Only when spelling was relevant-for example, in reading aloud - the preparation effect disappeared when targets were spelled with different onset letters. Roelofs (2006) proposed that preparation in speech production happens in terms of phonemes and that the spelling of a word only plays a role when it is relevant for the task at hand. Furthermore, he suggested that the results of Damian and Bowers (2003) may have been due to a strategy of the participants - that is, encoding the initial sound of the response words both in terms of phonology and orthography in memory, maybe because of the different language, that is, English versus Dutch.

\section{Conclusion}

The present results demonstrated the importance of phonological representations for visual word recognition. Consistent with the literature, phonological facilitation effects emerged within $50 \mathrm{msec}$ of prime exposure duration. This result might be taken as further evidence for the view that the masked onset priming effect is phonological in nature. Orthography, in contrast, was shown to play a rather limited role in reading Dutch words aloud. The fact that orthographic overlap did not yield any priming effect might be a result of the shallow orthography in Dutch, with a relatively clear correspondence between graphemes and phonemes. More cross-linguistic research is necessary to validate this hypothesis.

\section{AUTHOR NOTE}

This research was supported by a fellowship from the Royal Netherlands Academy of Arts and Sciences and by Grant 453-02-006 from the Netherlands Organization for Scientific Research. The experiment was carried out at the Max Planck Institute for Psycholinguistics in Nijmegen, The Netherlands. The author thanks Suzan Kroezen for setting up and running the experiment and Sachiko Kinoshita, Ken Forster, and Derek Besner for their comments on an earlier version of this article. Address correspondence to N. O. Schiller, Leiden Institute for Brain and Cognition, Leiden University, P.O. Box 9515, NL-2300 RA, Leiden, The Netherlands (e-mail: n.o.schiller@let.leidenuniv.nl).

\section{REFERENCES}

Batyen, R. H., Piepenbrock, R., \& Gulikers, L. (1995). The CELEX lexical database [CD-ROM]. Philadelphia: Linguistic Data Consortium, University of Pennsylvania.

Coltheart, M., Rastle, K., Perry, C., Langdon, R., \& Ziegler, J. (2001). DRC: A dual route cascaded model of visual word recognition and reading aloud. Psychological Review, 108, 204-256.

DAMIAN, M. F. (2001). Congruity effects evoked by subliminally presented primes: Automaticity rather than semantic processing. Journal of Experimental Psychology: Human Perception \& Performance, 27, 154-165.

Damian, M. F., \& Bowers, J. S. (2003). Effects of orthography on speech production in a form-preparation paradigm. Journal of Memory \& Language, 49, 119-132.

Ferrand, L., \& Grainger, J. (1992). Phonology and orthography in visual word recognition: Evidence from masked nonword priming. Quarterly Journal of Experimental Psychology, 45A, 353-372.

FERRAND, L., \& GRAINGER, J. (1993). The time course of orthographic and phonological code activation in the early phases of visual word recognition. Bulletin of the Psychonomic Society, 31, 119-122.

FERrand, L., \& Grainger, J. (1994). Effects of orthography are independent of phonology in masked form priming. Quarterly Journal of Experimental Psychology, 47A, 365-382.

Ferrand, L., Grainger, J., \& Segui, J. (1994). A study of masked form priming in picture and word naming. Memory \& Cognition, 22, 431-441. 
Forster, K. I., \& DAVIS, C. (1991). The density constraint on formpriming in the naming task: Interference effects from a masked prime. Journal of Memory \& Language, 30, 1-25.

Frost, R. (1998). Toward a strong phonological theory of visual word recognition: True issues and false trails. Psychological Bulletin, 123, 71-99.

Grainger, J., \& Ferrand, L. (1996). Masked orthographic and phonological priming in visual word recognition and naming: Cross-task comparisons. Journal of Memory \& Language, 35, 623-647.

Kinoshita, S. (2000). The left-to-right nature of the masked onset priming effect in naming. Psychonomic Bulletin \& Review, 7, 133-141.

Kinoshita, S. (2003). The nature of masked onset priming effects in naming: A review. In S. Kinoshita \& S. J. Lupker (Eds.), Masked priming: The state of the art (pp. 223-238). Hove, U.K.: Psychology Press.

Levelt, W. J. M., Roelofs, A., \& Meyer, A. S. (1999). A theory of lexical access in speech production. Behavioral \& Brain Sciences, 22, 1-75.

LUPKER, S. J. (1982). The role of phonetic and orthographic similarity in picture-word interference. Canadian Journal of Psychology, 36, 349-367.

Mulatti, C., Reynolds, M. G., \& Besner, D. (2006). Neighborhood effects in reading aloud: New findings and new challenges for computational models. Journal of Experimental Psychology: Human Perception \& Performance, 32, 799-810.

Perfetti, C. A., \& Bell, L. [C.] (1991). Phonemic activation during the first $40 \mathrm{~ms}$ of word identification: Evidence from backward masking and priming. Journal of Memory \& Language, 30, 473-485.

Perfetti, C. A., Bell, L. C., \& Delaney, S. M. (1988). Automatic (prelexical) phonetic activation in silent word reading: Evidence from backward masking. Journal of Memory \& Language, 27, 59-70.

RoElofs, A. (2006). The influence of spelling on phonological encoding in word reading, object naming, and word generation. Psychonomic Bulletin \& Review, 13, 33-37.

SCHILlER, N. O. (1998). The effect of visually masked syllable primes on the naming latencies of words and pictures. Journal of Memory \& Language, 39, 484-507.
SCHILlER, N. O. (2000). Single word production in English: The role of subsyllabic units during phonological encoding. Journal of Experimental Psychology: Learning, Memory, \& Cognition, 26, 512-528.

SCHILlER, N. O. (2004). The onset effect in word naming. Journal of Memory \& Language, 50, 477-490.

SCHILlER, N. O. (in press). The masked onset priming effect in picture naming. Cognition.

YAtes, M. (2005). Phonological neighbors speed visual word processing: Evidence from multiple tasks. Journal of Experimental Psychology: Learning, Memory, \& Cognition, 31, 1385-1397.

YAtes, M., Locker, L. JR., \& Simpson, G. B. (2004). The influence of phonological neighborhood on visual word perception. Psychonomic Bulletin \& Review, 11, 452-457.

\section{NOTES}

1. In earlier studies, I formally assessed that under these masking conditions, participants are generally not able to recognize the primes (see prime visibility tests reported in Schiller, 1998, p. 489, and Schiller, 2000 , p. 517). Informal interviewing of the participants at the end of the present experiment revealed that a few participants noticed some sort of flickering before the target word appeared on the screen. However, nobody was able to identify prime words between the masks. The current experiment was run in the same laboratory using the same equipment and prime exposure duration as were the experiments reported in the Schiller (1998) study.

2. One may argue that the stimulus set used in the present study revolves only around /s/ and $/ \mathrm{k} /$ as possible pronunciations of the grapheme $c$ and that we should be cautious interpreting results on the basis of such a relatively limited sample. However, one should keep in mind that the same target word was preceded both by primes starting with /s/ and by primes starting with $/ \mathrm{k} /$ in this study. Unfortunately, $c$ is the only simple grapheme that has an ambiguous pronunciation at the word onset in Dutch. Therefore, cross-linguistic research is needed involving languages like Spanish in which other phonological contrasts could be tested (e.g., /g/ vs. /y/) as in guitarra /gitara/ ("guitar") and gitano /ritano/ ("gypsy"). 
APPENDIX

Stimulus Materials From the Experiment

\begin{tabular}{|c|c|c|c|c|}
\hline \multirow[b]{2}{*}{ Targets } & \multicolumn{4}{|c|}{ Primes } \\
\hline & $\mathrm{P}-\mathrm{O}+$ & $\mathrm{P}+\mathrm{O}-$ & $\mathrm{P}+\mathrm{O}+$ & $\mathrm{P}-\mathrm{O}-$ \\
\hline \multicolumn{5}{|l|}{ Onset /k/ } \\
\hline congres (congress) & cement (concrete) & kachel (oven) & canvas & grendel (bolt) \\
\hline complot (conspiracy) & ceder (cedar) & kanse (pulpit) & cordon & divan (divan) \\
\hline consul $($ consul $)$ & censor (censor) & kussen (pillow) & cursus & pakket (package) \\
\hline cordon (cordon) & centrum (center) & karton (cardboard) & complex & haven (harbor) \\
\hline cultuur (culture) & citroen (lemon) & koppel (couple) & complot & fontein (fountain) \\
\hline contrast (contrast) & cider (cider) & kummel (caraway) & cultuur & parfum (perfume) \\
\hline canvas (canvas) & cycloon (cyclone) & koffie (coffee) & congres & bodem (floor) \\
\hline cursus (course) & circus (circus) & kolder (jerkin) & contrast & loket (counter) \\
\hline condor (condor) & cijfer (digit) & kapper (hairdresser) & campus & navel (navel) \\
\hline campus (campus) & cyclus (cycle) & korrel (grain) & consul & houweel (pickaxe) \\
\hline cortex $($ cortex $)$ & cirkel (circle) & kanker (cancer) & condor & hamster (hamster) \\
\hline complex (complex) & censuur (censorship) & karaf (pitcher) & cortex & lama (llama) \\
\hline \multicolumn{5}{|l|}{ Onset /s/ } \\
\hline centrum & cordon & sikkel (sickle) & circus & radar (radar) \\
\hline censuur & complex & soldaat (soldier) & cirke & rivier (river) \\
\hline citroen & cultuur & sonnet (sonnet) & censor & bliksem (lightning) \\
\hline cement & congres & sofa $($ couch $)$ & cycloon & pistool (gun) \\
\hline cijfer & condor & salto (somersault) & cider & nagel (nail) \\
\hline cider & contrast & servet (napkin) & cijfer & gebit (teeth) \\
\hline cycloon & canvas & satijn (satin) & cement & ladder (ladder) \\
\hline censor & consul & samba (samba) & citroen & harnas (armor) \\
\hline ceder & complot & sorbet (sorbet) & cyclus & buffel (buffalo) \\
\hline circus & cursus & service (service) & centrum & hengel (fishing rod) \\
\hline cirkel & cortex & sector (sector) & censuur & lasso (lasso) \\
\hline cyclus & campus & sandaal (sandal) & ceder & degen (sword) \\
\hline
\end{tabular}

(Manuscript received March 3, 2006;

revision accepted for publication July 5, 2006.) 